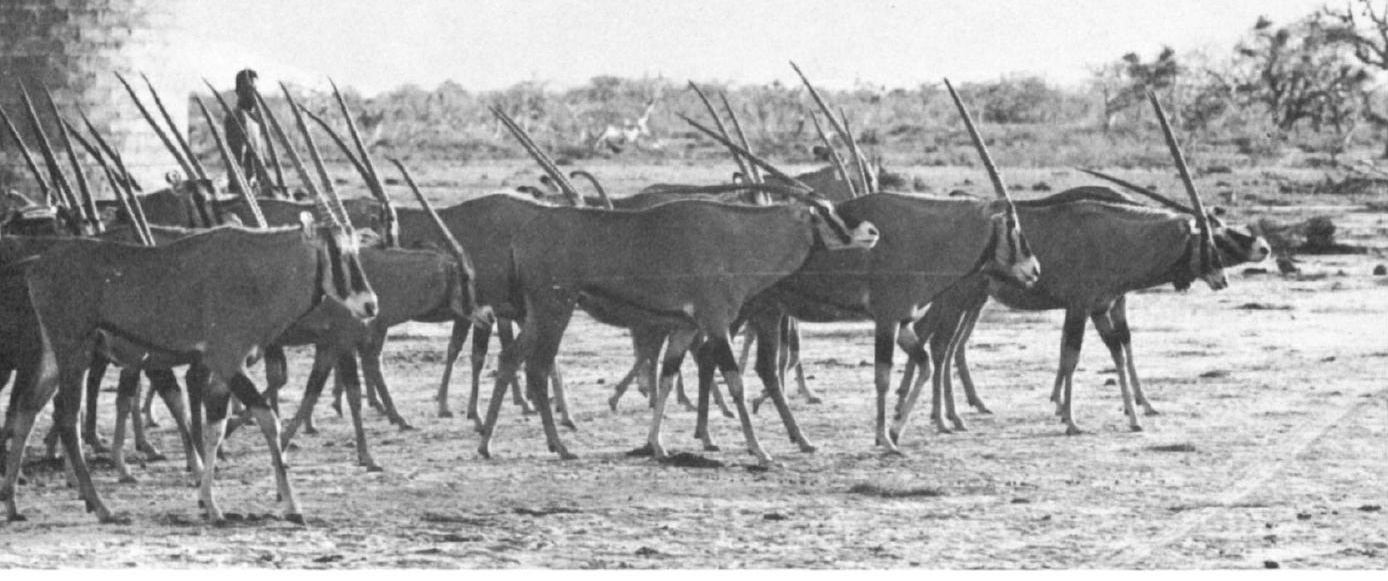

\title{
Fringe-eared Oryx on a Kenya Ranch
}

\section{Mark Stanley Price}

Experiments in domesticating fringe-eared oryx on a Kenya ranch suggest they could be an economic proposition in semi-arid areas, where domestic cattle can only be kept for a few months each year. Oryx have also proved superior to eland, at one time believed to be the most promising wild ungulate for domestication, largely because they feed by day, whereas in this climate eland feed at night, a time when domesticated animals have to be penned to protect them from predators, notably lions.

In 1970 a pilot project to ranch large ungulates by domesticating them was started on the Galana Ranch in south-east Kenya. The object was to combine cattle and wildlife in one area and find out whether domestication could provide another use for wildlife besides hunting. Most of the development and research costs of the project have been borne by the African Wildlife Leadership Foundation, supported by Galana Game and Ranching Ltd and the Kenya Game Department.

The ranch covers $5000 \mathrm{sq} \mathrm{km}$, about one per cent of Kenya, between the coast and Tsavo East National Park. The land is classed as arid bush, with maximum daily shade temperatures of $34^{\circ} \mathrm{C}$. Annual rainfall in the coastal bush on the eastern boundary is $600 \mathrm{~mm}$ but drops sharply to only $250 \mathrm{~mm}$ in the west, where it adjoins the Tsavo National Park. Early experience showed that the drier, western third of the ranch could support cattle for only a few months each year, following rain, so this seemed the best area in which to evaluate the potential of wild species as alternatives to cattle. Aerial censuses show good wildlife populations, estimated at 4000-6000 elephant, $6000-8000$ fringe-eared oryx Oryx beisa callotis, 50 black rhinoceros, 3000 buffalo, 3000 zebra, 1500 eland, 400 giraffe and imprecisely known numbers of gerenuk, lesser kudu, waterbuck, impala, Peter's gazelle and ostrich. Lion density is high; cheetah and leopard occur in smaller numbers. Currently, 17,000 head of cattle are kept.

So far, buffalo, eland, gazelle, ostrich and oryx have been captured on the Above: RELEASE IN THE MORNING 


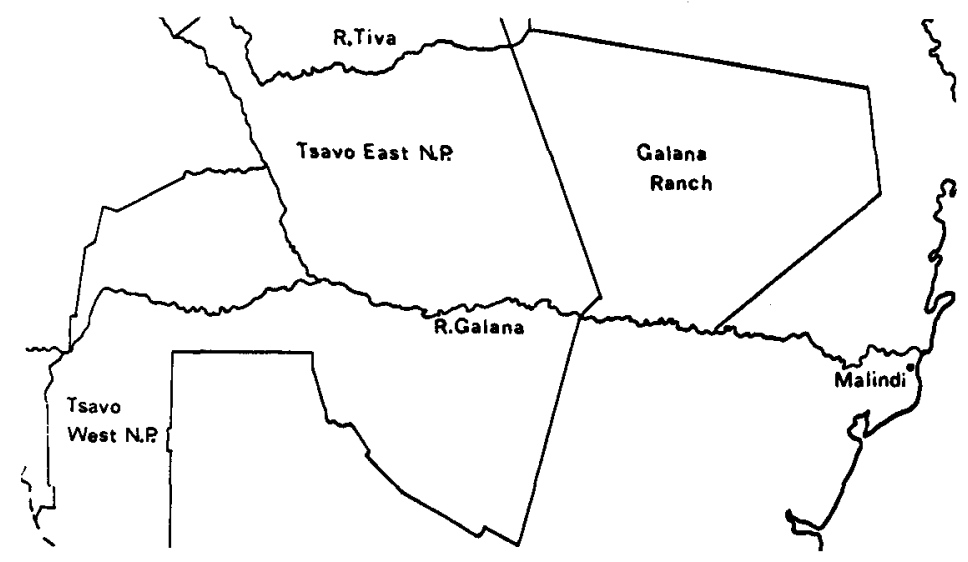

ranch and tamed, but all except the oryx have had overriding disadvantages for ranching, due either to temperament or performance under domesticated conditions. Much had been expected of the eland on the basis of other herds' performance in Africa, but their productivity was low. Moreover, domesticated eland have to be confined to pens at night to prevent scattering and predation by lions, but in this extreme climate wild eland feed largely by night to reduce their exposure to daytime temperatures, and they wander in their search for browse. Their adaptations to this environment are thus behavioral, whereas those of the oryx are physiological, and for this reason oryx appear to be the most promising domesticants in this environment.

The domestic oryx herd numbers about 150, with animals of all ages. Increases in numbers are mostly due to the capture of wild oryx within a few miles of the ranching area. Trapping is done with three vehicles which work like sheepdogs, driving the oryx into a funnel trap with a mouth $400 \mathrm{~m}$ wide and wings $500 \mathrm{~m}$ long that narrow to an apex where there is a holding pen; each animal is then put into a crush for inspection. Only those between weaning (about six months) and two years old are kept, and put into pens in groups of 10-12 of the same age. Taming proceeds gradually as they become used to being provided with cut grass containing species in their normal diet, supplemented with lucerne to maintain their condition.

Domestication is, therefore, no more than the habituation of oryx to the close proximity of humans, and their associated sounds and smells-cars, wheelbarrows, voices, radios. After a month in the pens they can be moved into a oneha paddock where food is still provided, and then into a 40 ha enclosure where they can forage, and are actively herded by one person who moves them around as a group and brings them back into the pen in the evening. After two weeks they can be integrated into an existing, larger herd ranging over unenclosed land. Their daily routine is then one of being penned at night, and feeding and watering by day under the supervision and protection of herders.

Oryx breed well under domestic conditions. With a gestation period of nine months, each breeding female unfailingly produces a calf every $10 \frac{1}{2}-11$ months; a higher reproductive rate would seem to be almost impossible physiologically. The ranch cattle, on the other hand, with the same gestation period, calve only about every 15 months. The oryx calve in pens without any human interference, and the mother is content to leave the calf 'lying-out' by day in the open while she feeds with the herd, and it is she who decides when the calf is ready to venture outside, usually at about three weeks old; by then it has been ear-tagged. 
high breeding rate they outpoint the cattle; their disadvantages are that each herd needs more herders, and losses are higher due to accident or return to the wild. The priority now is to increase the total numbers of oryx by 120 annually for the next two or three years to see whether the herd can be run as a commercially viable enterprise. Projections suggest that under the right conditions an oryx ranch can be worthwhile economically. Breeding animals are already available for commercial ranches or pastoral areas, and when total numbers have increased a programme of selective breeding will begin.

The ungulate species which have been tested as potential domesticants have provided enough comparative information to predict which wild species could in future be domesticated successfully. Experience with eland on Galana and further studies on their social behaviour in the wild ${ }^{2}$ explain why it is never likely to be a successful new domestic species, despite so much optimism a few years ago. ${ }^{3}$ The oryx project has also shown that when domesticated and kept in herds which approximate the composition of those in the wild, the oryx breed at a rate which is probably the physiological maximum for the species. This information is relevant to the breeding programme of the related and highly endangered Arabian oryx, for which a high increase rate in the captive world herd must be a priority: the published breeding rates for some zoos are not as high as for Galana's fringe-eared oryx. ${ }^{1}$ The Galana experiment has also found what constitutes a socially stable herd of domestic oryx, again information that is directly relevant for reintroducing the Arabian oryx into its former natural range.

\section{References}

1. DOLAN, J. M. 1976. The Arabian oryx Oryx leucoryx: its destruction, captive history and propogation. Int. Zoo Yb. 16.

2. HILLMAN, J. C. 1974. Ecology and behaviour of the wild eland. African Wildlife Leadership Foundation Wildlife News, 9, 3.

3. KYLE, R. 1972. Meat production in Africa-the case for new domestic species. Bristol Veterinary School.

\section{Forests Need Protection Too}

President Nyerere of Tanzania, opening the new Kilimanjaro National Park in July 1977, said: 'We should thank the colonialists for teaching us to care for our wildlife heritage in Tanzania. The people have understood the importance of protecting and preserving our wild animals. In fact now local leaders are asking that areas known to harbour a wild animal population should be set aside for conservation. This is good but not good enough because many have yet to understand the vital need to protect our forests in the same way.'

\section{Save Our Species-Especially the Wolf}

BBC-Television's 'Nationwide' news programme mounted a weekly 'SOS' (Save Our Species) feature in conjunction with the WWF and FPS. Each week animals in various zoos were featured and the public invited to make donations-some of the money going to the zoos concerned, a proportion of it to conservation, through WWF and FPS, and the remainder to conservation projects in other zoos. Over $£_{50,000}$ was raised, of which FPS received some $£ 2,500$. One of the interesting results of the Appeal was the relative popularity of the animals shown. Surprisingly, the largest amount of money raised was for the wolf. The remaining top ten, in order, were elephant, penguins, snow leopard, pygmy hippo, giant panda, cheetah, gorilla, tiger and Arabian gazelle. 